\title{
Experimental study of polymer injection enhanced oil recovery in homogeneous and heterogeneous porous media using glass-type micromodels
}

\author{
Seyed Javad Hosseini ${ }^{1} \cdot$ Jalal Foroozesh ${ }^{1}$
}

Received: 3 July 2017 / Accepted: 10 May 2018 / Published online: 1 June 2018

(c) The Author(s) 2018

\begin{abstract}
In water flooding process, volumetric sweep efficiency and oil recovery can be enhanced using polymer to increase the viscosity of water. As a result, polymer flooding has higher recovery as compared to water flooding due to front stability and reduction of fingering problem. In this research work, a set of polymer flooding runs were carried out using glass-type micromodels. The micromodels were fabricated to have homogeneous and heterogeneous flow patterns. They were positioned horizontally and saturated with a heavy crude oil sample taken from an Iranian oil field before starting the injection. Three commercial polymers were used in this study. Whole process was photographed continuously with a high-resolution camera to monitor the displacement of polymer solution in the micromodels. As a part of this study, the effect of different parameters including polymer solution concentration, injection flow rate and heterogeneity on performance of polymer flooding was investigated. On top of the regular homogeneous and heterogeneous flow patterns used in this study, a heterogeneous flow pattern mimicking sandstone reservoirs was created based on the image of a thin section of a sandstone (outcrop) and polymer front movement was observed during injection.
\end{abstract}

Keywords Polymer injection · Glass-type micromodel $\cdot$ Sweep efficiency

\section{Introduction}

Polymer is a large molecule built up by the addition of small repeating units (monomers) (Allcock et al. 2003). In general, the polymers used in the EOR process are divided into two groups of synthetic polymer and biopolymer. The unique features of each category of these polymers have caused advantage and disadvantage. Synthetic polymers have affordable prices, appropriate viscosity in fresh water and acceptable adsorption on the rock surface. The disadvantage of this type of polymer can be attributed to the sensitivity to flow rate and shear degradation. This type of polymer has low efficiency in high-salinity water. Biopolymers show excellent performance against high-salinity water and shear degradation but they can be sensitive to bacterial degradation in low-temperature reservoirs. Biopolymer does not

Jalal Foroozesh

jalal.foroozesh@gmail.com; jalal.foroozesh@utp.edu.my

1 Department of Petroleum Engineering, Universiti Teknologi PETRONAS, Seri Iskandar, Malaysia adsorb on rock surface (Sheng 2013; Sheng et al. 2015; Buchgraber 2008; Barati 2011).

When polymer is added to water (brine), its viscosity will be increased. Therefore, polymer injection can lead to changes in fractional flow and mobility ratio and also has fluid diversion effect. As a result, polymer can help with reduction of viscous fingering and improving of water injection profile that will lead to an improvement in sweep efficiency (Buchgraber 2008; Barati 2011; Sorbie 1991; Needham and Doe 1987; Chang 1978). Nevertheless, stability of polymer is an issue. Many researchers have focused on the parameters that affect the stability of polymers in different conditions. The factors of chemical, mechanical and biological degradation cause instability of the polymers. Oxidation and ferric ions are the factors affecting the chemical degradation. Reducing the amount of oxygen in the water in contact with the polymer prevents the generation of $\mathrm{Fe}^{3+}, \mathrm{Fe}^{2+}$ and free radical $\mathrm{O}^{2-}$ ions making the polymer solution to be more stable and prevents chemical degradation. Mechanical degradation occurs when polymer molecules break down due to shear stress. Flow rate has a significant impact on preventing this phenomenon and should be optimized. 
Biological degradation is more likely to occur in case of biopolymers, but under a few conditions; synthetic polymers can also be degraded biologically. Using some additives can solve these problems (Sheng et al. 2015; Sorbie 1991). Polymer injection in reservoirs will face some limitations. Reservoir water salinity, reservoir temperature, type of formation and reservoir permeability are factors influencing the performance of polymer injection. For example, in the case of polymer incompatibility with the reservoir fluid salinity and the ions contained therein, the viscosity of the polymer solution is not sufficiently achieved and its effectiveness is greatly reduced (Sheng et al. 2015; Needham and Doe 1987). The high temperature of the reservoir can break down the molecular chains of polymers and turns them into monomers. If these phenomena happen, the viscosity of the solution of water and polymer will be reduced. In most reports, a temperature tolerance of $93{ }^{\circ} \mathrm{C}$ for both types of polymer (synthetic polymer and biopolymer) is acceptable. It is worth noting that the temperature of $93{ }^{\circ} \mathrm{C}$ does not guarantee the stability of the polymer over a long period of time (Taber et al. 1997a, b). Most successful polymer injections have been in sandstone formations. The use of this technology in carbonate formations requires further investigation. Hence, the type of reservoir rock and the mineralogy of the rock is important (Jewett and Schurz 1970). The polymer is composed of large molecules. Therefore, the use of polymer in rocks with small pore-throat size is not recommended. This will cause the pore-throat to block. Pore-throat size will control the rock permeability. Therefore, rocks with low permeability as a result of having small pore size cannot be a good candidate for polymer injection (Jewett and Schurz 1970).

Field practice of polymer flooding is reported in the literature. The use of polymer as an additive for injection into oil reservoirs began in 1967 and has quickly become popular. So far, many fields have been under polymer injection. These include 'Taber south field', 'North Burbank unit', 'Brelum unit reservoir' and 'Vernon'. In all cases, the polymer injection has been effective. According to reports, except for a few cases, the injected polymer type was synthetic. An additional average recovery of $7 \%$ has been reported. Another notable case is the formation type that the polymer has been injected into it. Most formations under polymer injection have been sandstone rocks (Clampitt and Reid 1975; Lozanski and Martin 1970; Shaw and Stright 1975; Rowalt 1973).

Experimental study is an important step in the investigation of polymer injection. Core flooding is commonly used for experimental study. Core is one of the best representatives of the reservoir at the surface, but having native reservoir's core is not easy. Also, due to the lack of visualization of the core flooding in cases where the flow behavior is necessary, this porous media cannot be a good candidate. To overcome these problems, visual micromodels have been used. Glass micromodels are quite useful tools to study the active recovery mechanisms during polymer injection and the effective parameters in oil recovery (Danesh et al. 1987). Due to the transparency, the whole process can be directly observed and photographed and by using a digital image analysis (DIA), the photos that are taken during the process, can be analyzed for any pore level mechanism and also to estimate the recovery factor.

The challenges ahead when using micromodels are to create a porous media that can represent a real porous media. Many different pore patterns have been created in micromodels, each of which has its advantage and disadvantage. Figure 1 shows some of these micromodels (Danesh et al. 1987; Romero-Zeron and Kantzas 2007; Buchgraber et al. 2011; Farzaneh et al. 2012; Hamedi Shokrlu and Babadagli 2015; Howe et al. 2015; Bahari Moghaddam and Rasaei 2015; Manlowe and Radke 1990).

In the laboratory, a lot of experiments have been done on the polymer injection using micromodels. Heshmati et al. (2007) used a micromodel with two different permeability layers to study the effect of permeability heterogeneity on the performance of the polymer flooding. After polymer injection, a $17 \%$ increase in recovery was reported at best (Heshmati et al. 2007). Emami et al. (2008) employed a micromodel with five-spot injection pattern to examine the impact of local and global heterogeneity (similar to layered reservoirs) on recovery. The results of the experiments showed that the maximum recovery achieved when layers are perpendicular to mean flow direction. Also, the slope of the micromodel strongly affects the efficiency of the polymer injection process (Emami Meybodi et al. 2008). Hematpur et al. (2011) studied the effect of polymer injection in the presence of low-viscosity oil using a micromodel setup. The results showed that using the polymer of hydrolyzed polyacrylamide (HPAM) had the best performance under test conditions (Hematpour et al. 2011). Maghzi et al. (2011) used a micromodel setup with five-spot injection pattern to investigate the injection of the nanoparticles with polymer. An increase of $10 \%$ in recovery was the result of the experiments conducted by these researchers (Maghzi et al. 2011). Wegner and Ganzer (2013) compared the results of polymer flooding in a micromodel with numerical simulation (Wegner and Ganzer 2013). Yousefvand and Jafari (2015) investigated the polymer efficiency in the presence of nanosilica particles. The investigation was done in a micromodel using reservoir oil and brine (Yousefvand and Jafari 2015). Sedaghat et al. (2015) investigated the performance of alkaline surfactant polymer (ASP) injection for heavy oil recovery using fractured five-spot micromodels. Hydrolyzed polyacrylamide showed a better performance as compared to other polymers (Sedaghat et al. 2015). Rock et al. (2017) investigated the behavior of viscoelastic polymers in a porous media using a glass micromodel setup. The 

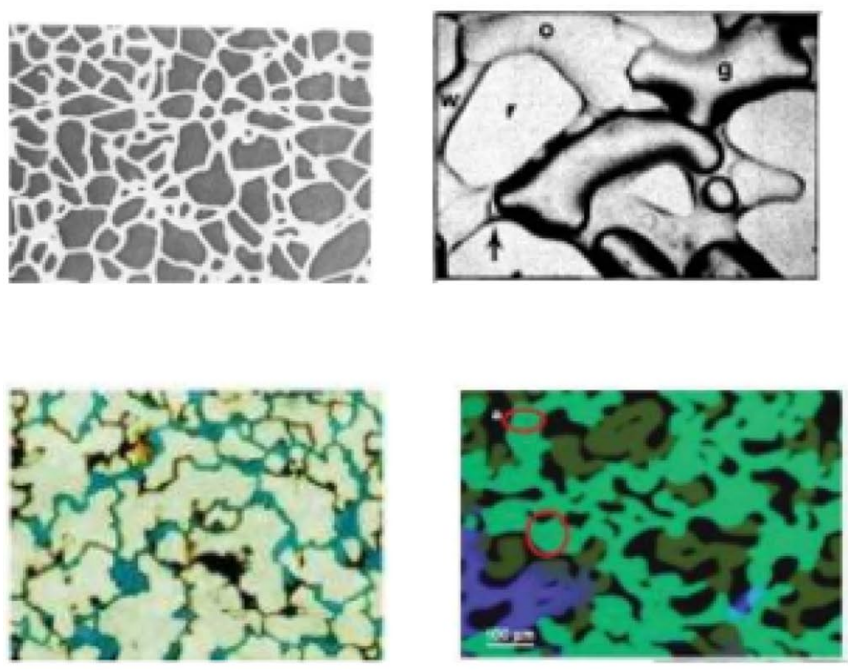
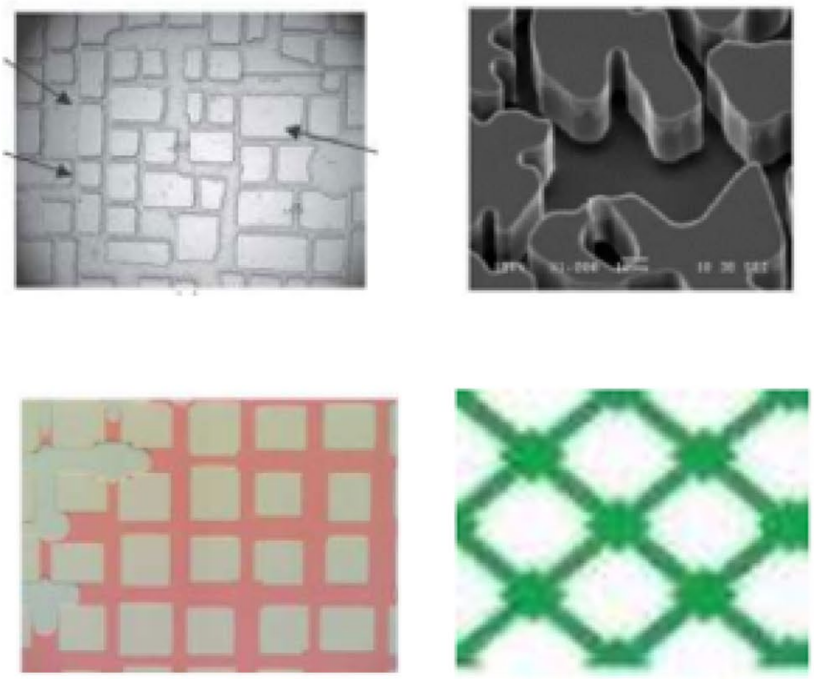

Fig. 1 Micromodel pore patterns

two factors of salinity and mechanical degradation had the high impact on the results presented by these researchers. The results obtained by these researchers showed that there is a relationship between shear thickening and elastic flow instability (Rock et al. 2017).

It is inferred that the performance of polymer flooding can be dependent on reservoir type and characteristic and micromodel setups can be used to study it. Therefore, in this research, a number of micromodel setups with different heterogeneities of pore patterns have been fabricated to study the performance of three different polymers in an Iranian oil field.

\section{Experimental procedure and materials}

The primary objective of the undertaken series of experiments was to investigate the effect of different parameters such as polymer solution concentration, polymer type and injection flow rate on oil recovery. Hence, three different types of commercial polymer were used to prepare the polymer solution with different concentrations and were injected at different flow rates. The specifications of the polymers are given in Table 1 . These polymers are used in drilling industry as an additive to water-based muds for mainly fluid loss control.

The first step was to fabricate a glass micromodel which was a relatively time-consuming procedure. The steps involved in the fabrication process were first using a piece of mirror with appropriate dimensions and then removing the paint coated on the backside until the mercury coating was exposed. Then, we covered a layer of plastic laminate on the mercury coating and the pattern in black and white printed on a paper, overlaid on the laminate surface. Ultraviolet (UV) exposure was used to polymerize the nonpattern area (resistant to acid) and then by means of nitric acid, the non-polymerized (pattern) area was removed (dissolved) and then the hydrofluoric acid was used to etch the pattern area. Cyclic submersion in hydrofluoric acid for a certain time can lead to a certain depth of etching. It should be mentioned that all the steps were taken under complete caution. A number of micromodel setups with homogeneous and heterogeneous flow patterns were built and used for experimental study of polymer injection. Figure 2 shows a homogenous flow pattern used for micromodel fabrication. The heterogeneous micromodels will be explained later on.

The next step was to saturate the micromodel setup with the crude oil without having any connate water saturation.
Table 1 The specifications of the polymers used in this study

\begin{tabular}{llll}
\hline $\begin{array}{l}\text { Polymer } \\
\text { type no. }\end{array}$ & Commercial name & Provider & Polymer family \\
\hline 1 & DRISPAC $^{\circledR}$ Superlo & \\
2 & DRISPAC $^{\circledR}$ Regular & Chevron Phillips Chemical Company & Polyanionic cellulose \\
3 & DRISCAL $^{\circledR} \mathrm{D}$ & Chevron Phillips Chemical Company & Polyanionic cellulose \\
& & & $\begin{array}{c}\text { Polyacrylamide (syn- } \\
\text { thetic polymer) }\end{array}$ \\
\hline
\end{tabular}




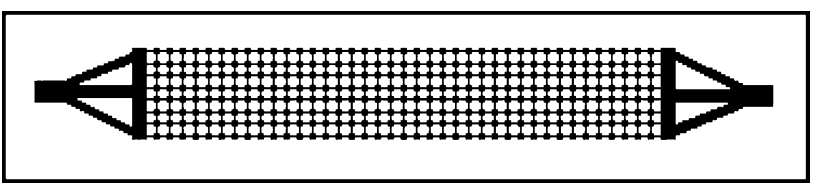

Fig. 2 Homogenous flow pattern

The crude oil used in this study was taken from one of the Iranian oil fields which is located in the southern part of Iran and has an API of 19.8 (relatively heavy). The saturation process was done very carefully to avoid any penetration of crude oil through the non-porous media, rather than etched porous media. Figure 3 shows a sample of saturated flow pattern with crude oil.

After the flow pattern is saturated, the experiment was started. Quizix pump was used in this study to inject the polymer solution into the micromodel at a very precise rate close to real velocity of fluid in the reservoir.

\section{The physical properties of micromodel}

As one of the important stages of the experiment, the properties of the generated glass micromodel were determined. Some of these properties, namely pore volume and porosity were determined by means of computer software using digital image analysis (DIA) process. Some other properties such as permeability were measured experimentally by steady-state flow test after stabilization of differential pressure $(\Delta P)$ across the setup. It should be noted that the micromodels used here are water-wet as made by glass and no aging process has been carried out to change their original wettability.

\section{Porosity}

Using DIA process, the areal porosity was determined and with regard to uniform distribution of etching depth, the porosity was calculated and reported as a total porosity. The pattern was saturated with oil and then the picture was taken and analyzed to determine the porosity. Using image analysis, the total porosity estimated was $0.36(36 \%)$.

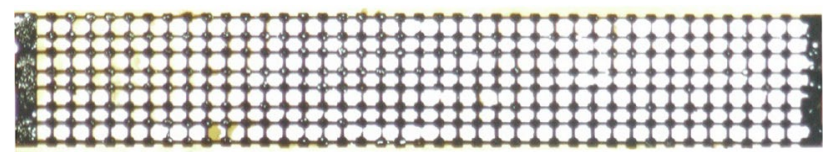

Fig. 3 Sample of homogenous flow pattern saturated with crude oil (dark color is oil; white color is grain)

\section{Pore volume}

The depth of etched glass (pores) created in micromodel was measured by Micrometer tool. Therefore, by multiplying the depth by pore area, pore volume was determined as $0.068 \mathrm{cc}$. A magnified view of the etched glass is shown in Fig. 4.

\section{Permeability}

Another important property of glass micromodel which should be determined was absolute permeability. This could be achieved by gathering the flow rate data and the related injection pressure. So, the flow rate was set and let the system to reach the constant (stabilized) pressure difference. By knowing the pressure difference (outlet pressure is atmospheric pressure), the absolute permeability can be calculated by Darcy's law. The permeability of homogenous pattern measured was around 20 Darcy.

\section{Results and discussion}

\section{Homogeneous flow pattern}

\section{Effect of polymer solution concentration on oil recovery}

Three polymer solutions with different concentrations (1000, 1500 and $2250 \mathrm{ppm}$ ) of polymer type 1 were prepared and injected at the rate of $0.0002 \mathrm{cc} / \mathrm{min}$ to the oil-saturated homogenous micromodel to study the effect of polymer concentration on oil recovery. Figure 5 shows the effect of polymer solution concentration on oil recovery for polymer type 1 .

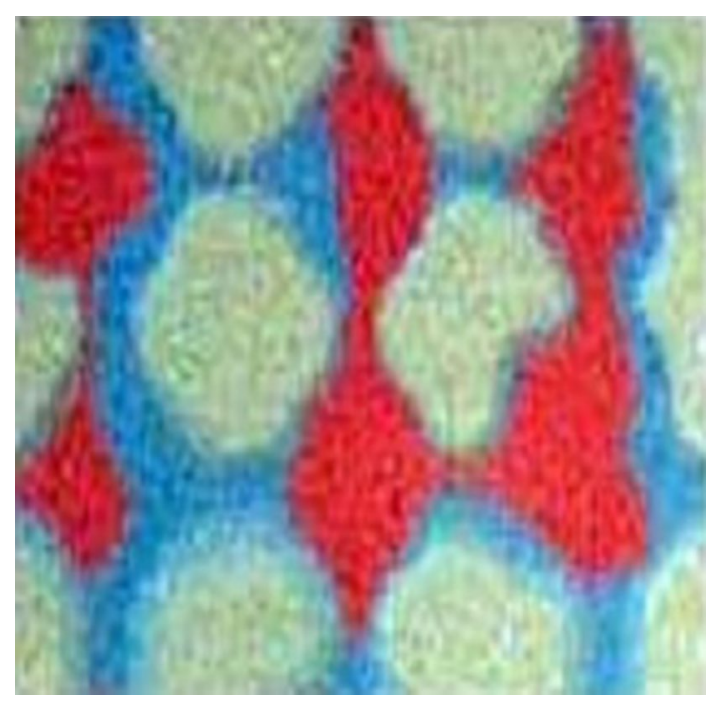

Fig. 4 A magnified view of the etched glass (blue and red colors refer to water and oil phases, respectively) 


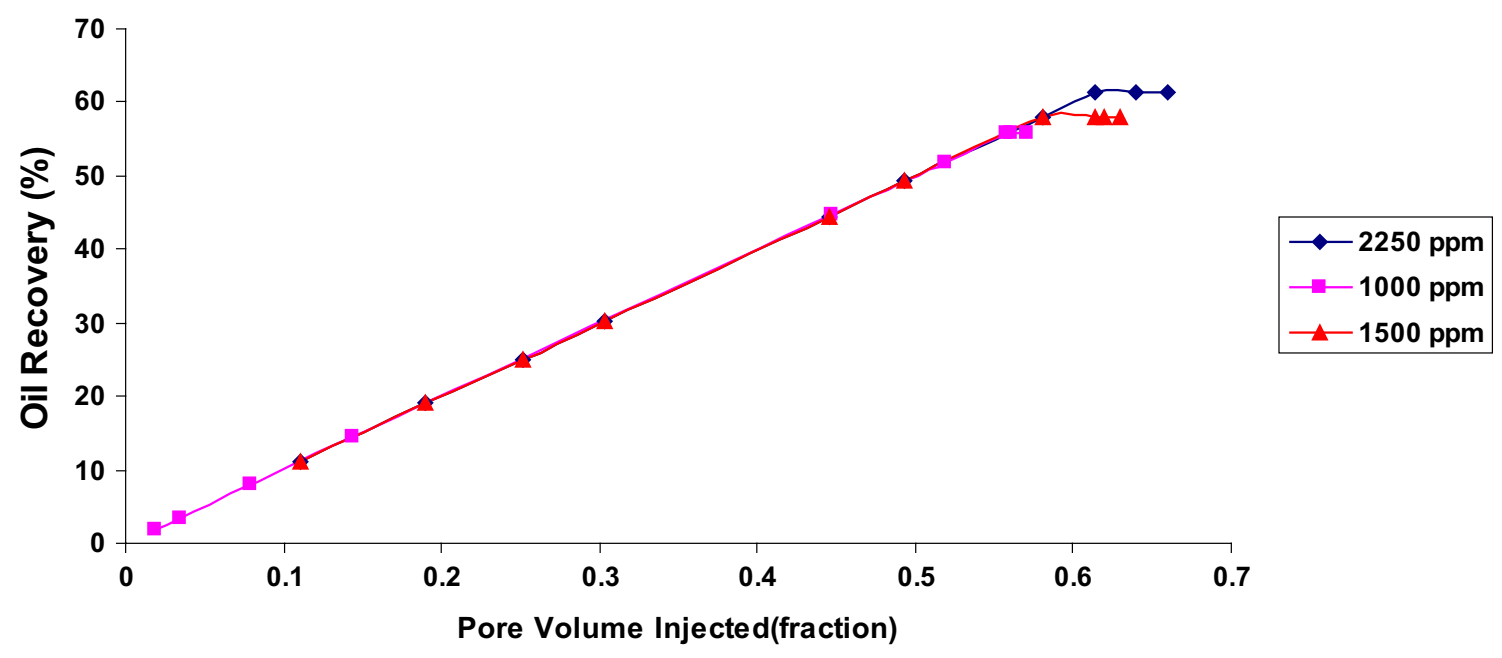

Fig. 5 Comparison between oil recoveries by three different concentrations of polymer solutions of polymer type $1($ flow rate $=0.0002 \mathrm{cc} / \mathrm{min})$

Table 2 Measured physical properties of water and polymer solutions at room temperature $\left(T=24^{\circ} \mathrm{C}\right)$

\begin{tabular}{lll}
\hline Material & Viscosity $(\mathrm{cp})$ & Density $\left(\mathrm{g} / \mathrm{cm}^{3}\right)$ \\
\hline Water & 0.94 & 1.01 \\
Polymer type 1 $(c=1000 \mathrm{ppm})$ & 1.44 & 1.01 \\
Polymer type 1 $(c=1500 \mathrm{ppm})$ & 1.98 & 1.01 \\
Polymer type 1 $(c=2250 \mathrm{ppm})$ & 4.15 & 1.02 \\
Polymer type 2 $(c=1500 \mathrm{ppm})$ & 7.14 & 1.01 \\
Polymer type 3 $(c=1500 \mathrm{ppm})$ & 3.24 & 1.01 \\
\hline
\end{tabular}

As it can be seen in Fig. 5, for $150 \%$ increase in polymer concentration in solution (from 1500 to $2250 \mathrm{ppm}$ ), the recovery has increased around $7 \%$. Enhancement of polymer concentration increases solution viscosity resulting in front stability and minimizes fingering and channeling problem, which lead to higher oil recovery.

As it can be observed in Fig. 5, the lower concentration (1000 ppm) solution had the fastest breakthrough among all at 0.54 pore volume $(\mathrm{PV})$ injected, while the other solutions had later breakthrough at 0.58 and $0.62 \mathrm{PV}$ injected for 1500 and $2250 \mathrm{ppm}$, respectively. Lower concentration translates to lower viscosity (which is shown in Table 2) and lower sweep efficiency (see Fig. 6). It should be mentioned that for all our experiments, once there was no more oil production, the injection was ceased shortly.

Figure 6 shows the profile of injected polymer in micromodel for low and high concentrations at three different pore volumes. As it can be seen, at high concentration of $2250 \mathrm{ppm}$, the polymer displacement is more towards positon-like as compared to the profile of low concentration of $1000 \mathrm{ppm}$. This could sweep more area occupied by oil. Table 2 shows that the viscosity of polymer type 1 is $1.44 \mathrm{cp}$ at concentration of $1000 \mathrm{pm}$ and it is $4.15 \mathrm{cp}$ at concentration of $2250 \mathrm{pm}$ resulting in a better sweep efficiency. In micromodel setup, it is not possible to investigate the vertical conformance and sweep due to the nature of the equipment but the role of polymer injection and gel treatment in conformance control in oil reservoirs has been discussed in the literature (Kantzas et al. 1999; Suleimanov and Veliyev 2016).

\section{Effect of injection flow rate on oil recovery}

In these series of experiments, three different flow rates were tested: $0.0002,0.0005$ and $0.0008 \mathrm{cc} / \mathrm{min}$ for the polymer type 1 and 0.0002 and $0.0005 \mathrm{cc} / \mathrm{min}$ for polymer types 2 and 3, all at fixed concentration of $1500 \mathrm{ppm}$. As it can be observed, in each step, the flow rate has been increased by a factor of 2.5. Figure 7 shows the effect of injection flow rate for the polymer type 2 .

As it can be seen in Fig. 7, at lower flow rate, the polymer displacement in the model is more piston-like while at high injection rate, it is having unstable front with less pistonlike displacement. Similar results were observed for polymer types 1 and 3 . This is because, at low injection rates, fluid has time to distribute areally to have a more piston-like flow.

It should be noted that sensitivity of oil recovery to polymer injection rate during polymer flooding is also affected by low injectivity of polymer solution compared to water injection (Van den Hoek et al. 2012). Loss of injectivity especially in low-permeability formations is a serious problem in polymer flooding projects, which can occur because of large molecule size and high viscosity of polymer solutions. In real reservoirs, high injection rates can cause the bottom-hole pressure to rise up and if not controlled, exceed the fracture pressure and cause formation damage. 
Fig. 6 Front stability for low-concentration (1000 ppm) polymer solution and high-concentration (2250 $\mathrm{ppm})$ polymer solution at pore volumes of $0.2,0.5$ and 1 , polymer type 1 , injection rate; $0.0002 \mathrm{cc} / \mathrm{min}$, injection point on the left side (brown color: oil, whitish blue color: polymer)
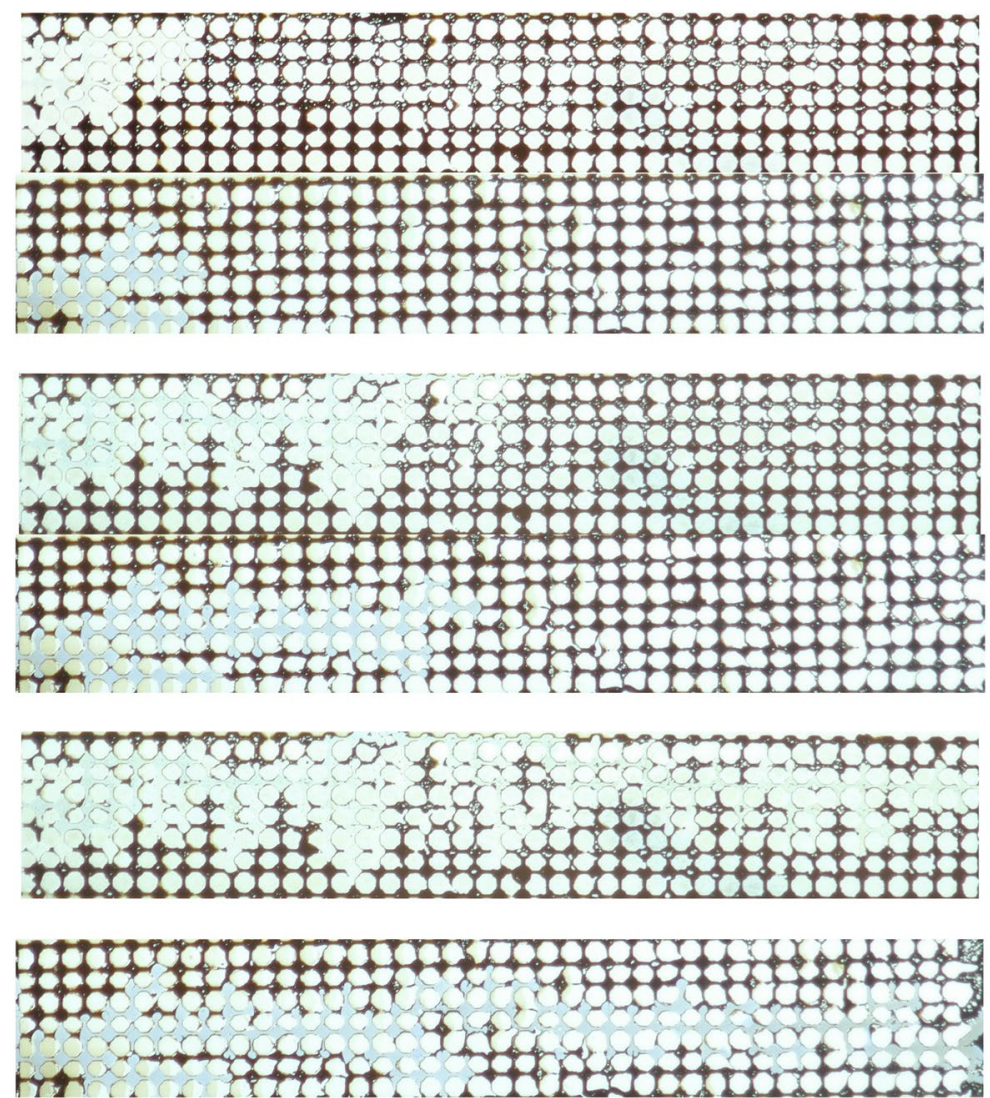

$0.2 \mathrm{PV}$

(high concentration)

$0.2 P V$

(low concentration)

0.5PV

(high concentration)

0.5PV

(low concentration)

1 PV

(high concentration)

1PV

(low concentration)
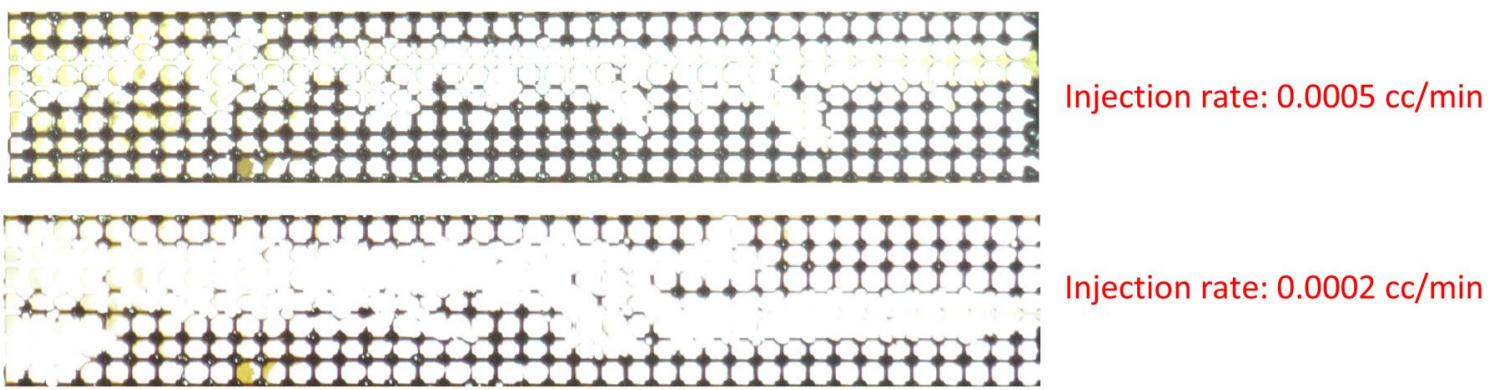

Fig. 7 Comparison between flooded pattern at breakthrough time for polymer type 2 for flow rates 0.0002 cc/min (lower side picture) and $0.0005 \mathrm{cc} / \mathrm{min}$ (upper side picture) both at concentration $=1500 \mathrm{ppm}$. Injection point on the left side (brown color: oil, white color: polymer)

\section{Comparison between water injection and polymer injection}

Water injection was done to compare its performance with polymer injection. Water flooding is one of the most favorable secondary recovery methods due to the availability of water (especially in offshore operation) and the relatively low cost and complexity compared to the other EOR methods. Nevertheless, the mobility of water needs to be controlled especially in layered and heterogeneous reservoirs to have a good conformance control. Adding polymer to water will increase the viscosity as it was discussed earlier and will increase the volumetric sweep efficiency. Figure 8 compares the displacement of water and polymer in the micromodel at three different pore volumes. Figure 8 clearly illustrates the better areal sweep efficiency and also less residual oil trapped in the pores and throats resulted from polymer flooding as compared to water injection leading to a higher oil recovery factor.

\section{Comparison of performance of the three polymer types}

Figure 9 compares the displacement of polymer types 1,2 and 3 in the micromodel at the same pore volume injected. They all have the fixed concentration of $1500 \mathrm{ppm}$. It can be

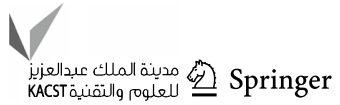




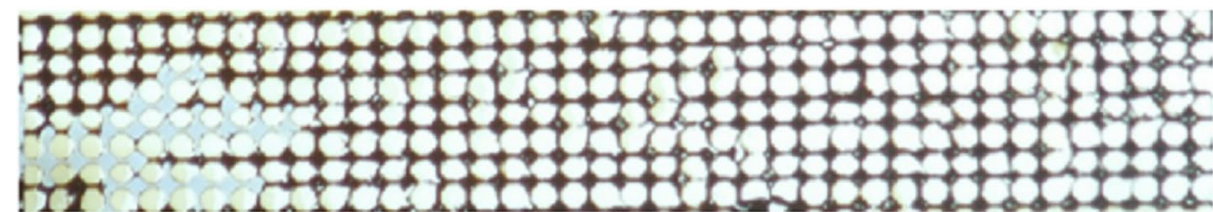

0.2PV

(Polymer)

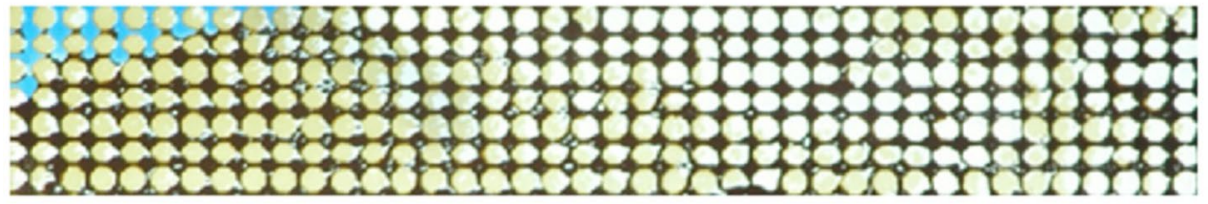

$0.2 \mathrm{PV}$

(Water)

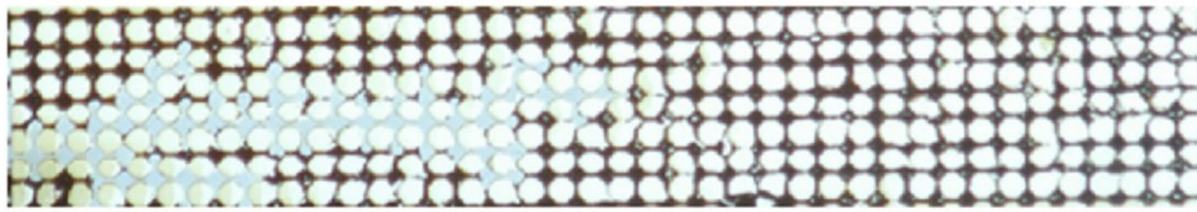

$0.5 \mathrm{PV}$

(Polymer)

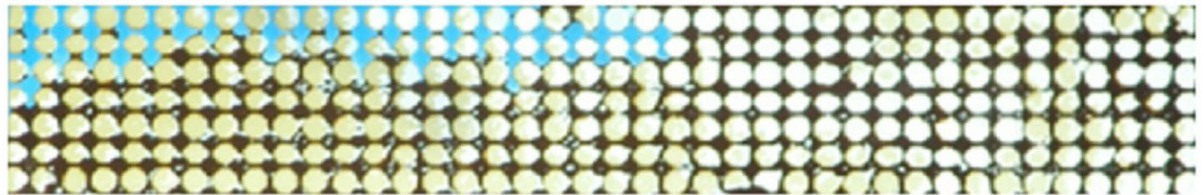

0.5PV

(Water)

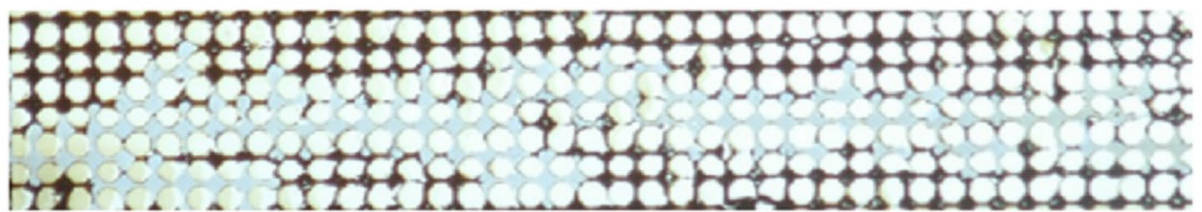

1PV

(Polymer)

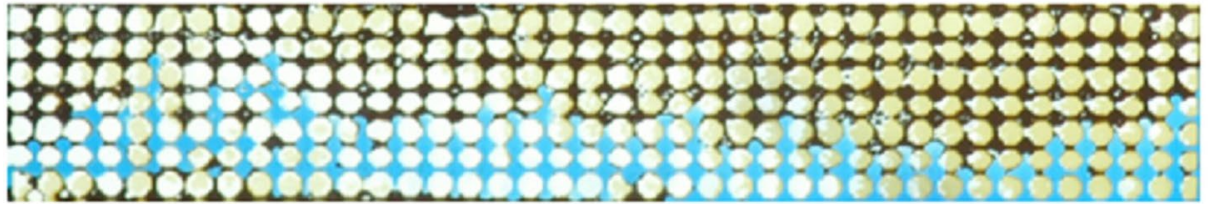

1PV

(Water)

Fig. 8 Flooded patterns at equal pore volumes injected for water flooding and polymer flooding, Polymer type 1 , injection rate $=0.0002 \mathrm{cc} / \mathrm{min}$, concentration $=1500 \mathrm{ppm}$ (brown color: oil, whitish blue color: polymer and blue color: water)

Fig. 9 Comparison between displacement of polymer type 1,2 and 3 at fixed concentration of $1500 \mathrm{ppm}$ (identical pore volume injected)

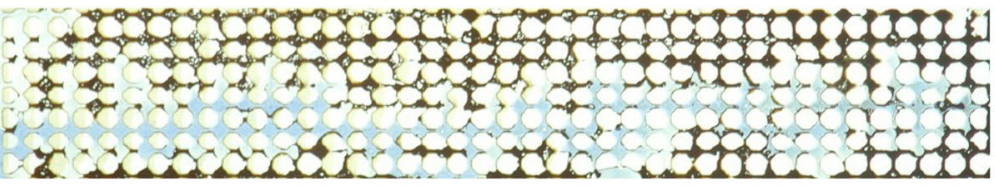

Polymer type 1

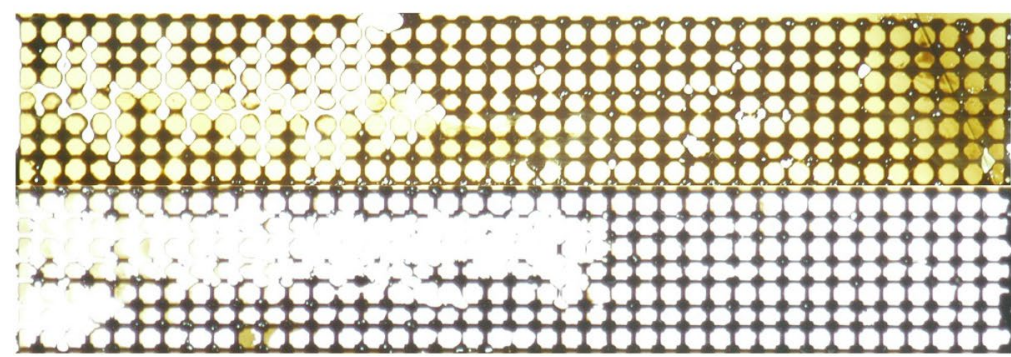

Polymer type 2

Polymer type 3 
observed that the displacement of polymer type 2 is more piston-like (i.e., stable displacement) as compared to two other polymers. Next, polymer type 3 is displacing like a piston. This could be explained by considering the viscosity of polymer solutions presented in Table 2 . As it given in Table 2, the solution of polymer type 2 has largest viscosity and after that polymer type 3 has a higher viscosity as compared to polymer type 1 . These viscosity values have led to a better mobility ratio of polymer type 2 resulting in a more stable displacement.

\section{Heterogeneous flow patterns}

Real oil reservoirs are complex set of different heterogeneities. But, in the majority of the routine reservoir engineering calculations, this heterogeneity is not considered. In routine core-flooding experiments also the effect of heterogeneity cannot be considered due to the small scale of core plugs. Hence, inclusion of heterogeneity in glass micromodels enables us to create different kind of heterogeneity and to visualize the polymer front movement and behavior from the beginning to the end of the experiment. In the following section, the results of polymer flooding in the artificially created heterogeneous patterns will be discussed. It should be mentioned that type of heterogeneity has been inherited from some real large-scale heterogeneities, which frequently can be found in subsurface reservoirs.

\section{Two-layered flow pattern}

This flow pattern includes two layers with different permeability (layers are separated by a red dashed line). The lower side layer has lower permeability compared to the upper side layer which has higher permeability. These different permeabilities have been obtained by controlling the size of the pores and throats in each layer. This is one of the heterogeneities that can be found in layered and segregated reservoirs.

As it can be seen in Fig. 10, the polymer is injected from the left and has been mainly advanced in bottom side with higher permeability. Although the upper layer has lower permeability as compared to lower layer, its area is large causing polymer to move through it too. It should be noted that the permeabilities of micromodels are generally large making the upper layer to also have a large permeability (in order of several Darcys) but smaller than the permeably of the lower side layer. That means, the contrast between layers' permeability may not cause much difference in flow behavior through different layers. It is worth mentioning that, due to the horizontal positioning of the micromodel pattern, there is not any effect of gravity involved.

\section{Faulted heterogeneous flow pattern}

In this flow pattern, the aim was to simulate the fault effect (faulted layer) on flow condition in real reservoirs during polymer injection. There are two layers in this pattern which have different permeability (high and low) which are faulted in the middle point of the flow pattern (normal fault) as shown in Fig. 11. As it can be seen, mimicking a faulted reservoir and due to displacement of zones, high- and lowpermeable zones are juxtaposed.

As it can be observed in Fig. 11, when the polymer front has reached the fault, it was diverted through the
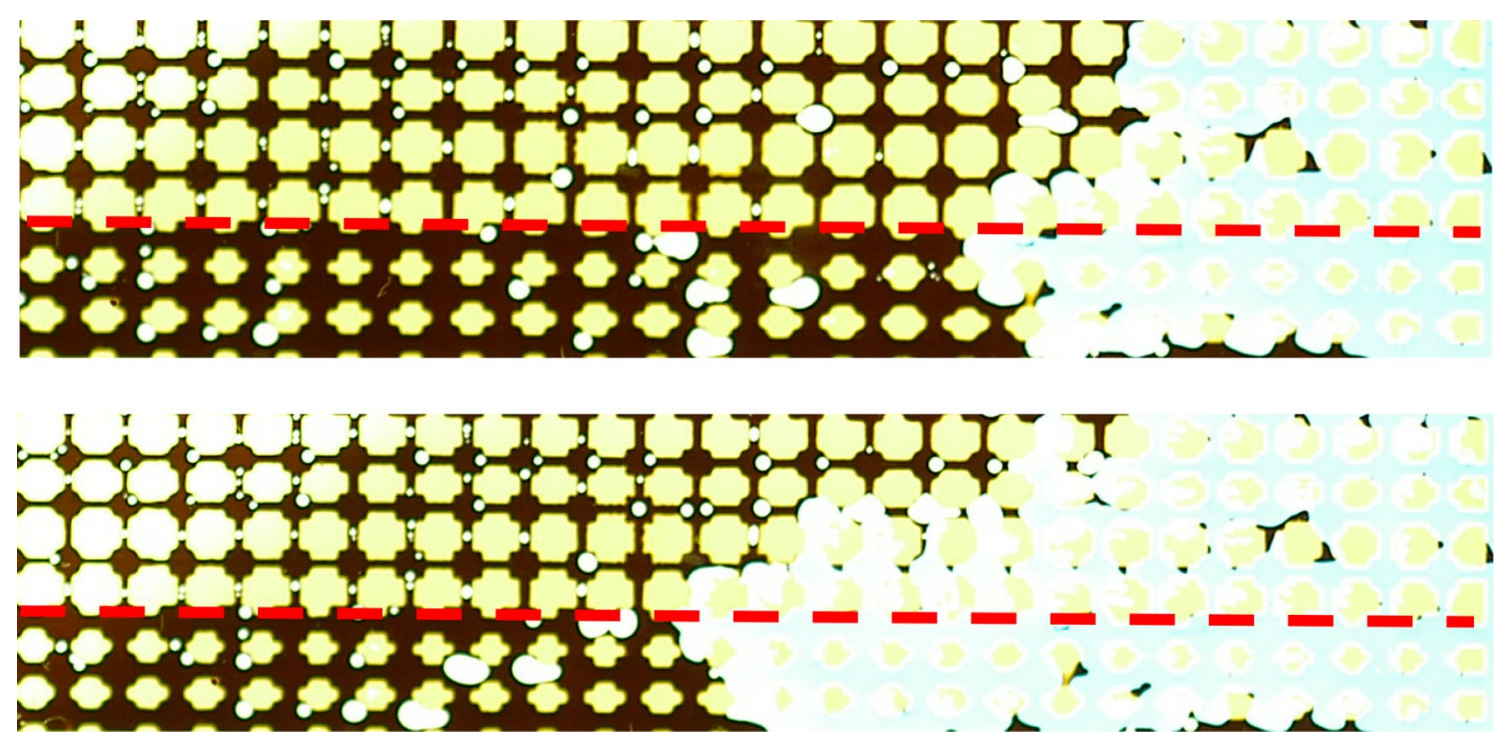

Fig. 10 Polymer front advancement in two-layered heterogeneous flow pattern, injection point on the right, upper side picture after 0.2 PV injected, lower side picture after 0.4 PV injected (brown color is oil, yellow color is grain and whitish blue color is polymer solution) 
high-permeable zone on the top-right side of the figure. It should be noted that the stream line was not 1-D (in $x$-direction) anymore and polymer breakthrough will potentially take longer time comparing to the 1-D flow. In real reservoirs, faults can change the flow direction and affect the volumetric sweep efficiency.

\section{Tilted zone heterogeneous flow pattern}

In this heterogeneous flow pattern, tilted zones have been placed adjacent to each other with low and high permeability, alternatively as shown in Fig. 12.

Polymer front movement in this flow pattern is zig-zag shape due to the permeability contrast between tilted zones. In this flow pattern, when polymer front has reached lowpermeable zone, it has tried to move forward (1-D) longitudinally while in high-permeable zone, the movement is both longitudinally and transverse (2-D).

\section{Flow pattern fabricated using a sandstone thin section}

Using the picture of a thin section from an outcropped sandstone, this flow pattern was fabricated. The primary objective was to simulate more real porous media to study fluid flow. It should be noted that this thin section is a small section of a rock which heterogeneity cannot be captured at this scale. However, tortuosity, dead-end pore effect and irregular pore and throat shapes still can be observed to some extent. Figure 13 shows the micromodel with sandstone flow pattern that is saturated with oil.

Figure 14 shows a magnified image of polymer solution-oil interface inside this flow pattern.

As it is observed in this, due to the high viscosity of polymer solution comparing to water injection which was shown before in Fig. 8, there is less residual oil trapped in the corners of pores and specifically in throats leading to a better displacement efficiency with minimum

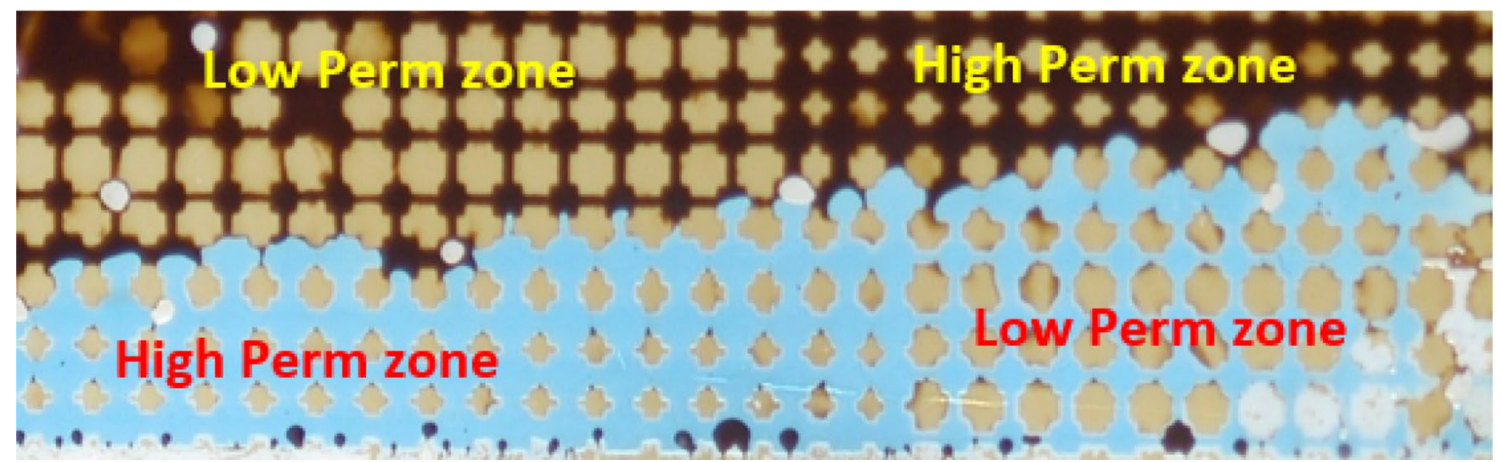

Fig. 11 Polymer front movement in quadratic flow pattern, polymer is injected from the left (brown color is oil, light yellow color is grain and blue color is polymer solution)

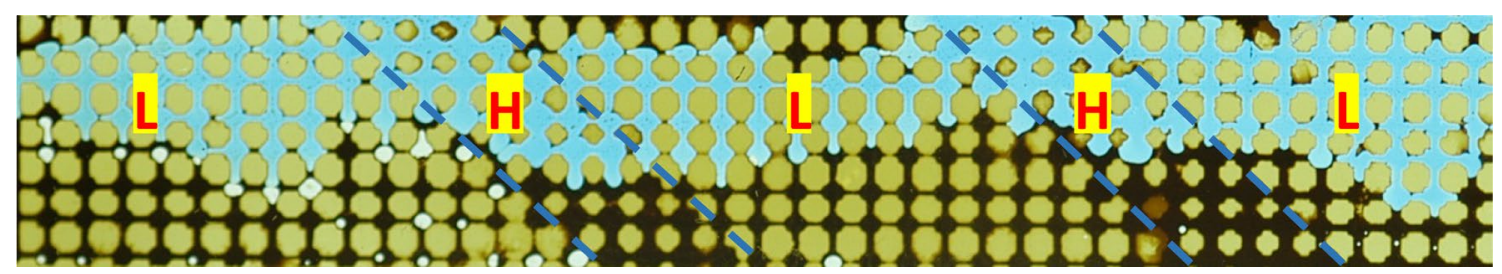

Fig. 12 Polymer front movement in tilted-stripped layered flow pattern (high- and low-permeable layers alternate each other; injection from right side; blue dashed lines are zone borders; $L$ low-permeable zone, $H$ high-permeable zone)

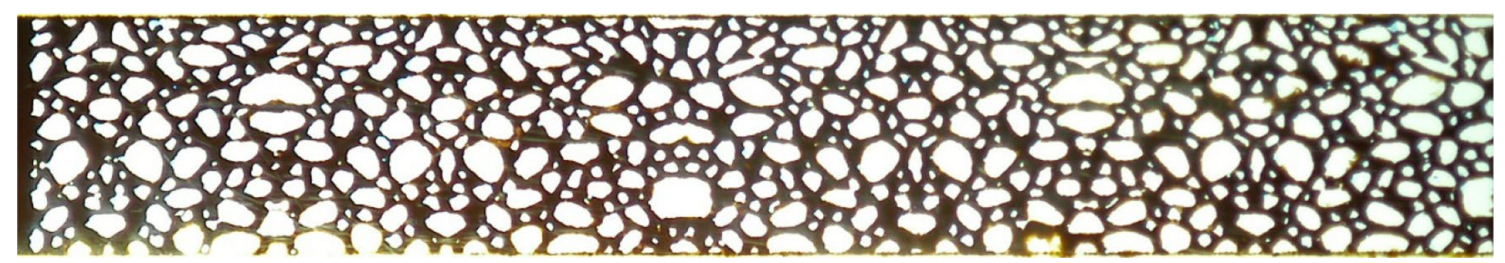

Fig. 13 Oil-saturated sandstone flow pattern (grains in white color)

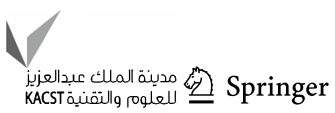




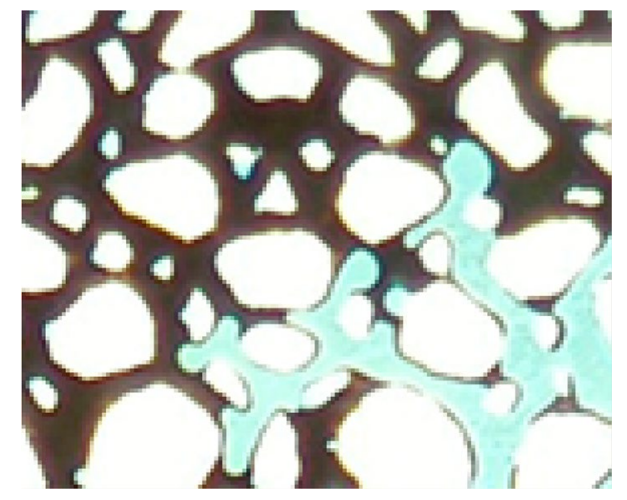

Fig. 14 Oil-polymer solution interface in sandstone flow pattern during polymer flooding (polymer solution in light blue and oil in brown colors)

oil-bypassing during the injection. This figure shows the efficiency of polymer flooding in systems with more realistic flow patterns.

\section{Summary and conclusions}

A set of polymer flooding experiments was performed in manually fabricated glass homogeneous and heterogeneous micromodels in horizontal positioning having 1-D or 2-D flow direction. The micromodel setup was saturated with a relatively heavy Iranian crude oil. The oil recovery results were compared with oil recovery from water flooding under the same initial conditions. Three different polymer types were used during this experimental study. The polymer solution concentration and injection rate were changed to account for their effects on oil recovery. The results showed a better performance for polymer type 2. It was also observed that at higher polymer concentrations and lower injection rates, a better sweep efficiency can be achieved by the polymer. Visualization of polymer front inside the micromodel showed a more piston-like movement of solution as compared to the front in pure water injection. Heterogeneity, as another studied parameter in this research, had an important role in oil recovery. Several artificially made heterogeneities were introduced into glass micromodels aiming to simulate the real heterogeneity in the reservoirs. As a result, swept area was significantly affected by heterogeneity since it affects the front movement. Therefore, macroscopic heterogeneities such as layered or faulted reservoirs and also existence of any high- or low-permeable zones must be taken into account before any polymer injection project to achieve the best EOR performance.
Open Access This article is distributed under the terms of the Creative Commons Attribution 4.0 International License (http://creativeco mmons.org/licenses/by/4.0/), which permits unrestricted use, distribution, and reproduction in any medium, provided you give appropriate credit to the original author(s) and the source, provide a link to the Creative Commons license, and indicate if changes were made.

\section{References}

Allcock HR, Lampe FW, Mark JE (2003) Contemporary polymer chemistry, Third edn, Pearson Education, New York

Bahari Moghaddam M, Rasaei MR (2015) Experimental study of the fracture and matrix effects on free-fall gravity drainage with micromodels. SPE J 20:Issue 02

Barati N (2011) Study of polymer flooding performance in the presence of nanoparticles. Master Thesis, Petroleum University of Technology

Buchgraber M (2008) An enhanced oil recovery micromodel study with associative and conventional polymers. Diploma Thesis, University of Leoben, Austria

Buchgraber M, Clemens T, Castanier LM, Kovscek A (2011) A microvisual study of the displacement of viscous oil by polymer solutions. SPE Reserv Eval Eng 14:Issue 03

Chang HL (1978) Polymer flooding technology yesterday, today, and tomorrow. J Petrol Technol 30:Issue 08

Clampitt RL, Reid TB (1975) An economic polymer flood in the North Burbank Unit, Osage County, Oklahoma. Fall meeting of the Society of Petroleum Engineers of AIME, 28 September-1 October, Dallas

Danesh A, Peden JM, Krinis D, Henderson GD (1987) Pore level visual investigation of oil recovery by solution gas drive and gas injection. SPE annual technical conference and exhibition, 27-30 September, Dallas, Texas

Emami Meybodi H, Kharrat R, Ghazanfari MH (2008) Effect of heterogeneity of layered reservoirs on polymer flooding: an experimental approach using 5-spot glass micromodel. Europec/ EAGE conference and exhibition, 9-12 June 2008, Rome, Italy

Farzaneh SA, Dehghan AA, Ghazanfari MH, Kharrat R (2012) A comparative study on WAS, SWAS, and solvent-soak scenarios applied to heavy-oil reservoirs using five-spot glass micromodels. J Can Pet Technol 51:Issue 05

Hamedi Shokrlu Y, Babadagli T (2015) Pore-scale investigation of phase distribution and residual-oil development during secondary and tertiary solvent injection. SPE Reserv Eval Eng 18:Issue 01

Hematpour H, Mardi M, Edalatkhah S, Arabjamaloe R (2011) Experimental study of polymer flooding in low-viscosity oil using one-quarter five-spot glass micromodel. Pet Sci Technol 29:1163-1175

Heshmati M, Mahdavi H, Haghighi M, Torabi M (2007) Visualization of polymer flooding in heterogeneous system using glass micromodels. J Sci 332:25-32

Howe AM, Clarke A, Mitchell J, Staniland J, Hawkes LA (2015) Visualising surfactant EOR in core plugs and micromodels. SPE Asia Pacific enhanced oil recovery conference, 11-13 August, Kuala Lumpur, Malaysia

Jewett RL, Schurz GF (1970). Polymer flooding — a current appraisal. JPT 22:675-684

Kantzas A, Burger D, Pow M, Cheung V, Mourits F (1999) Design strategies for improved conformance using polymer gels. Pet Soc Can. https://doi.org/10.2118/99-13-18

Lozanski WR, Martin P (1970) Taber South-Canada's first polymer flood. J Cdn Pet Tech 1970:99 
Maghzi A, Mohebbi A, Kharrat R, Ghazanfari MH (2011) Porescale monitoring of wettability alteration by silica nanoparticles during polymer flooding to heavy oil in a five-spot glass micromodel. Transp Porous Med 87:653-664

Manlowe DJ, Radke CJ (1990) A pore-level investigation of foam/oil interactions in porous media. SPE Reserv Eng 5:Issue 4

Needham RB, Doe PH (1987) Polymer flooding review. J Pet Technol

Rock A, Hincapie RE, Wegner J, Ganzer L (2017) Advanced flow behavior characterization of enhanced oil recovery polymers using glass-silicon-glass micromodels that resemble porous media. SPE Europec featured at 79th EAGE conference and exhibition, 12-15 June, Paris, France

Romero-Zeron LB, Kantzas A (2007) The effect of wettability and pore geometry on foamed-gel-blockage performance. SPE Reserv Eval Eng 10:Issue 02

Rowalt RJ (1973) A case history of polymer water flooding-Brelum field unit. Paper SPE 4671 presented at the SPE-AIME 48th annual fall meeting, Las Vegas, Sept. 30-Oct. 3, 1973

Sedaghat M, Mohammadzadeh O, Kord S, Chatzis I (2015) Pore-level experimental investigation of ASP flooding to recover heavy oil in fractured five-spot micromodels. EUROPEC 2015, 1-4 June, Madrid

Shaw RA, Stright DH Jr (1975) Performance of the Taber South Polymer Flood. Paper CIM 75-41 presented at the CIM 26th Annual Technical Meeting, Banff, June 11-13, 1975

Sheng JJ (2013) Chapter 3-polymer flooding - fundamentals and field cases. Enhanc Oil Recov Field Case Stud 2013:63-82
Sheng JJ, Leonhardt B, Azri N (2015) Status of polymer-flooding technology. J Can Pet Technol 54:Issue 02

Sorbie KS (1991) Polymer-improved oil recovery, 1st ed. CRC Press, Inc, Boca Raton

Suleimanov BA, Veliyev EF (2016) Nanogels for deep reservoir conformance control. Soc Pet Eng. https://doi.org/10.2118/18253 4-MS

Taber JJ, Martin FD, Seright RS (1997a) EOR screening criteria revisited-part 2: applications and impact of oil prices. SPE Reserv Eng 12:Issue 03

Taber JJ, Martin FD, Seright RS (1997b) EOR screening criteria revisited-part 1: introduction to screening criteria and enhanced recovery field projects. SPE Reserv Eng 12:Issue 03

Van den Hoek P, Mahani H, Sorop T, Brooks D, Zwaan M, Sen S, Saadi F (2012) Application of injection fall-off analysis in polymer flooding. Soc Pet Eng. https://doi.org/10.2118/154376-MS

Wegner J, Ganzer L (2013) Numerical analysis of polymer micromodel flooding experiments. In: Hou M, Xie H, Were P (eds) Clean energy systems in the subsurface: production, storage and conversion. Springer series in geomechanics and geoengineering. Springer, Berlin

Yousefvand H, Jafari A (2015) Enhanced oil recovery using polymer/ nanosilica. Procedia Mater Sci 11:565-570

Publisher's note Springer Nature remains neutral with regard to jurisdictional claims in published maps and institutional affiliations. 